\title{
553 - A promising Dutch initiative for highly intelligent seniors affected by dementia: a qualitative evaluation of Studiegroepen day time activities in long term care
}

\author{
Authors \\ Ruslan Leontjevas, ${ }^{1,2}$ \\ Monique Luyendijk, ${ }^{3}$ \\ Rico Kremer, ${ }^{3}$ \\ Debby L. Gerritsen ${ }^{1}$ \\ ${ }^{1}$ Department of Primary and Community Care, Radboud University Medical Centre, Radboud \\ Institute for Health Sciences, Radboudumc Alzheimer Center, Nijmegen, The Netherlands \\ ${ }^{2}$ Faculty of Psychology, Open University of The Netherlands, Heerlen, The Netherlands \\ ${ }^{3}$ Respect, wonen-zorg-welzijn, The Hague, The Netherlands
}

Background: Long term care organisations in the Netherlands organize day time activities for people with dementia who receive care at home to prevent burden of informal caregivers. Clients with dementia that are characterised as highly educated and/or highly intelligent often refuse to participate in such activities. Boredom, a lack of association with and unwillingness to mix with other participants are often reported. In 2006, the spiritual counselling department of long term care organisation Respect, The Hague, started with Studiegroepen (pronounced 'studee-groo-pen', study groups). This initiative provides adjusted leisure activities and group conversations about present-day topics and shared life experiences. Existential philosophical themes form the basis for discussions. Although Studiegroepen seems very successful and there are long waiting lists, the program is barely studied and is unknown in other organisations.

Aims: (1) to explore the opinions of the participants, their informal caregivers (mainly partners), and spiritual counsellors about Studiegroepen and the way the program meets the participants needs for autonomy, competence and relatedness (Self Determination Theory); (2) for the development of implementation material for other organisations, the aim was to reveal specific components of the program and to explore their barriers and facilitators.

Results: A thematic analysis in Atlas.ti of semi-structured interviews with 15 clients, eight informal caregivers and four spiritual counsellors revealed extremely positive evaluations. There were strong indications that the program meets clients' needs for autonomy, competence and relatedness. A striking example of a positive evaluation was a cancellation of relocation of a client-partner couple due to the lack of Studiegroepen in that city. Results suggest positive effects on mood, and quality of life. Several informal caregivers perceived a delay in dementia progression. The research revealed specific program components and barriers and facilitators to implement them.

Conclusions: Studiegroepen is a very positively evaluated initiative for highly educated and/or highly intelligent long time care clients with dementia living at home. This initiative should be systematically studied and described, while implementation material needs to be developed. This may help to introduce the program in other organisations and to further explore effects on outcomes in participants, and in informal caregivers. 